\title{
Formation and Deuterium Fractionation of Organic Molecules on Grain Surfaces
}

\author{
Naoki Watanabe \\ Institute of Low Temperature Science, Hokkaido University, Sapporo, JAPAN \\ email: watanabe@lowtem.hokudai.ac.jp
}

\begin{abstract}
A series of experiments on the surface reactions of hydrogen and deuterium atoms with solid $\mathrm{CO}$, formaldehyde $\left(\mathrm{H}_{2} \mathrm{CO}\right)$, and methanol $\left(\mathrm{CH}_{3} \mathrm{OH}\right)$ has been performed. Successive hydrogenation of $\mathrm{CO}$ on surfaces at $\sim 10 \mathrm{~K}$ was found to proceed efficiently via tunneling to produce $\mathrm{H}_{2} \mathrm{CO}$ and $\mathrm{CH}_{3} \mathrm{OH}$ on dust grains under the typical conditions of molecular clouds. Formation rates are strongly dependent on the surface temperature and composition. The role of surface reactions in the formation of deuterated formaldehyde and methanol was investigated. The deuterium fractionation of methanol observed in molecular clouds was reproduced experimentally via $\mathrm{H}-\mathrm{D}$ substitution in solid methanol at an accreting atomic $\mathrm{D} / \mathrm{H}$ ratio of 0.05-0.1. This is the first evidence that grain-surface reactions can be responsible for fractionation. We have determined several effective rate constants for hydrogenation, deuteration, and $\mathrm{H}-\mathrm{D}$ substitution to construct the surface reaction network for $\mathrm{CO}, \mathrm{H}_{2} \mathrm{CO}, \mathrm{CH}_{3} \mathrm{OH}$, deuterated formaldehyde, and deuterated methanol.
\end{abstract}

Keywords. astrochemistry — dust, extinction - ISM: molecules - molecular processes

\section{Introduction}

In observations, large numbers of solid-phase molecules have been discovered on interstellar dust in molecular clouds. Among the observed solid-phase molecules, primordial species such as CO must first be produced in the gas phase and subsequently freeze on a cold dust surface, while it is widely accepted that the formation of the dominant $\mathrm{H}_{2} \mathrm{O}$ molecules and more complex species requires surface chemical processes (for a review see Ehrenfreund \& Charnley 2000; Boogert \& Ehrenfreund 2004). Many experiments have been performed to simulate grain-surface processes and to analyze the observed infrared absorption spectra. These experiments were successful to some extent in revealing the importance of the photolysis and ion-bombardment of ice and in enabling the molecular assignment of the observed spectra. However, quantitative information on surface processes such as reaction channels, reaction rates, and activation energies, has yet to be obtained. In particular, details of nonenergetic processes, namely, surface reactions of light atoms, are as yet not well known despite their importance in the cold quiescent region.

Formaldehyde $\left(\mathrm{H}_{2} \mathrm{CO}\right)$ and methanol $\left(\mathrm{CH}_{3} \mathrm{OH}\right)$ have been found abundantly in not only interstellar ice (e.g., Keane et al. 2001) and but also in comets (e.g., Crovisier \& Bockelée-Morvan 1999). It has been reported that pure gas-phase reactions (e.g., Shalabiea \& Greenberg 1994) and UV photolysis of $\mathrm{H}_{2} \mathrm{O}-\mathrm{CO}$ ice (Allamandola et al. 1988; Schutte et al. 1996) are insufficient for explaining the observed abundances of these organic molecules in interstellar ice. In proton bombardment experiments, Hudson and Moore (1999) demonstrated that, over 4.6 billion years in space, yields of $\mathrm{H}_{2} \mathrm{CO}$ and $\mathrm{CH}_{3} \mathrm{OH}$ from $\mathrm{H}_{2} \mathrm{O}-\mathrm{CO}$ ice would be up to $7 \%$ and $12 \%$, respectively. This process is effective for explaining the production of methanol in a comet's nucleus only. Theoretical 
models suggest that the successive addition of hydrogen atoms (hydrogenation) to CO:

$$
\mathrm{CO} \stackrel{k_{1}}{\longrightarrow} \mathrm{HCO} \stackrel{k_{2}}{\longrightarrow} \mathrm{H}_{2} \mathrm{CO} \stackrel{k_{3}}{\longrightarrow} \mathrm{CH}_{3} \mathrm{O}, \mathrm{CH}_{2} \mathrm{OH} \stackrel{k_{4}}{\longrightarrow} \mathrm{CH}_{3} \mathrm{OH}
$$

where $k_{\mathrm{n}}$ is the reaction rate, takes place on the dust surface via tunneling reactions through activation barriers as large as $1000-2000 \mathrm{~K}$ and produce $\mathrm{H}_{2} \mathrm{CO}$ and $\mathrm{CH}_{3} \mathrm{OH}$ even at a temperature of approximately $10 \mathrm{~K}$ (Tielens \& Allamandola 1987; Tielens \& Whittet 1997). These models stimulated experimental works on the hydrogenation of CO. Hiraoka et al. $(1994 ; 2004)$ experimentally investigated this reaction system with an $\mathrm{H}$ atom spray apparatus. They observed only a small amount of $\mathrm{H}_{2} \mathrm{CO}$ and no $\mathrm{CH}_{3} \mathrm{OH}$ products upon exposure of pure solid $\mathrm{CO}$ to $\mathrm{H}$ atoms and concluded that the hydrogenation of $\mathrm{CO}$ would be too slow to produce $\mathrm{H}_{2} \mathrm{CO}$ and $\mathrm{CH}_{3} \mathrm{OH}$ on a grain surface. Unfortunately, however, they did not experimentally estimate the flux of hydrogen atoms that they used. The estimation of the $\mathrm{H}$ flux or fluence is essential to determine the efficiency of reactions in molecular clouds. The comparison of our experimental results described below and theirs enabled us to estimate their flux to have been $10^{12} \mathrm{~cm}^{-2} \mathrm{~s}^{-1}$ or less. This low flux most likely explains their results (Hidaka et al. 2004; Watanabe et al. 2005).

Recent observations have revealed that the abundances of some deuterated interstellar molecules are markedly larger than the cosmic $\mathrm{D} / \mathrm{H}$ ratio of $10^{-5}$. In particular, deuterium fractionation in methanol was found in not only molecular clouds (Parise et al. 2003; 2004) but also in comets (Crovisier et al. 2004), and the ratio of deuterated methanol to normal $\mathrm{CH}_{3} \mathrm{OH}$ in column density observed toward a low-mass protostar is up to approximately 0.4 . Hereafter, the term $\mathrm{X}-d_{\mathrm{n}}$ will either denote an isotopomer with a specific number $\mathrm{n}$ deuterium atoms $\left(\mathrm{e} . \mathrm{g} . \mathrm{X}-d_{2}\right)$ or, if a general $\mathrm{n}$ appears, will refer to all deuterated isotopomers of a molecule. It is difficult to reproduce the observed Denrichments with pure gas-phase models. Although some gas-grain models have been proposed that achieve the observed level of D-enrichments of interstellar methanol, they are rather ambiguous due to the lack of information about grain-surface reactions such as reaction channels and the rates of hydrogenation and deuteration. It is therefore highly desirable to experimentally clarify the role of grain-surface reactions in D-enrichments.

Here, we present the results of our series of recent experiments regarding hydrogenation and deuteration of solid $\mathrm{CO}, \mathrm{H}_{2} \mathrm{CO}, \mathrm{D}_{2} \mathrm{CO}$, and $\mathrm{CH}_{3} \mathrm{OH}$.

\section{Experimental}

Two pieces of apparatus, LAboratory Setup for Surface reactions in Interstellar Environment (LASSIE) and Apparatus for SUrface Reaction in Astrophysics (ASURA), were constructed on the basis of the same concept for experiments on the surface reactions of atoms. Both systems are of basically the same design and described elsewhere (Hidaka et al. 2004; Watanabe et al. 2004, 2005). The experiments were performed with LASSIE or ASURA. The reactions of $\mathrm{H}$ and $\mathrm{D}$ atoms with solid $\mathrm{CO}, \mathrm{H}_{2} \mathrm{CO}$, and $\mathrm{D}_{2} \mathrm{CO}$ were measured mainly using LASSIE and those with methanol using ASURA. In addition, we sometimes also measured the same reaction system using both LASSIE and ASURA to crosscheck the validity of the experiments. The composition of the samples investigated were $\mathrm{CO}-\mathrm{H}_{2} \mathrm{O}$ mixed ice, $\mathrm{CO}(1 \mathrm{eML})$ on $\mathrm{H}_{2} \mathrm{O}$ ice, pure solid $\mathrm{CO}, \mathrm{H}_{2} \mathrm{CO}$ (1 eML) on $\mathrm{H}_{2} \mathrm{O}$ ice, $\mathrm{D}_{2} \mathrm{CO}(1 \mathrm{eML})$ on $\mathrm{H}_{2} \mathrm{O}$ ice, and pure solid methanol $\left(-d_{\mathrm{n}}\right)$. Here, the term " 1 eML" represents the equivalent amount of molecules for one monolayer of a flat surface. Since the surface of amorphous $\mathrm{H}_{2} \mathrm{O}$ ice is very rough, 1 eML of molecules cannot cover the entire surface area and some $\mathrm{H}_{2} \mathrm{O}$ molecules will be exposed on the surface. That is, 1 eML does not represent a coverage of unity. 
Solid samples were produced by vapor deposition on an aluminum substrate cooled by a closed-type He refrigerator. In the present work, the surface temperature was varied from 8 to $20 \mathrm{~K} . \mathrm{H}_{2} \mathrm{CO}$ and $\mathrm{D}_{2} \mathrm{CO}$ gases were produced by the thermal cracking of paraformaldehyde (purity 99.8\%, Merck) and paraformaldehyde- $d_{2}$ (purity 99\%, ACROS) powders, respectively. The powders were heated to $57^{\circ} \mathrm{C}$ in a glass vacuum tube. It was necessary to maintain the gas line and the variable leak valve at approximately $60^{\circ} \mathrm{C}$ in order to prevent condensation of $\mathrm{H}_{2} \mathrm{CO}$ inside the gas line. The composition of the solid samples were measured using a Fourier transform infrared spectrometer at resolutions of $0.5 \mathrm{~cm}^{-1}$ for pure solid $\mathrm{CO}$ and $\mathrm{CO}-\mathrm{H}_{2} \mathrm{O}$ mixed ice and $4 \mathrm{~cm}^{-1}$ for $\mathrm{H}_{2} \mathrm{CO}, \mathrm{CO}-\mathrm{H}_{2} \mathrm{O}$ mixed ice, and methanol.

Details of the atomic source have been described elsewhere (Hidaka et al. 2004; Watanabe et al. 2005). Briefly, $\mathrm{H}$ and $\mathrm{D}$ atoms were produced by the dissociation of $\mathrm{H}_{2}$ and $\mathrm{D}_{2}$ molecules in a microwave-induced plasma in a Pyrex glass tube (25 $\mathrm{mm}$ in diameter). Atoms were transferred via a series of two polytetrafluoroethylene (PTFE) tubes to the solid target. The downstream PTFE tube was tightly covered with an oxygen-free copper pipe connected to the cold head. This simple arrangement produces very low temperature atomic hydrogen (Walraven \& Silvera 1982). In the present study, the beam line was cooled to $30-50 \mathrm{~K}$, as measured using $\mathrm{Au} / \mathrm{Fe}-0.07 \%$ chromel thermocouples attached to the PTFE tube at the most downstream end. We carefully eliminated the contamination in the atomic source.

The measurement of atomic flux is essential for the determination of the reaction rates and the efficiency of reactions in space. In our experiments, the fluxes of atoms were measured using a quadrupole mass spectrometer (QMS) with a Faraday cup, calibrated with an ion gauge. During the flux measurements, the substrate was de-installed and the QMS head was set at the original position of the substrate in alignment with the beam line. The typical dissociation fraction was approximately $15 \%$ at least. The $\mathrm{H}$ atom fluxes were in the range of $5 \times 10^{14}-1 \times 10^{15} \mathrm{~cm}^{-2} \mathrm{~s}^{-1}$.

\section{Results and Discussion}

\section{1. $\mathrm{H}+\mathrm{CO}-\mathrm{H}_{2} \mathrm{O}$ Mixed Ice and $\mathrm{H}+\mathrm{CO}(1 \mathrm{eML})$ on $\mathrm{H}_{2} \mathrm{O}$ Ice}

CO- $\mathrm{H}_{2} \mathrm{O}$ mixed ice $\left(\mathrm{CO} / \mathrm{H}_{2} \mathrm{O} \sim 0.25\right)$ was exposed to the cold $\mathrm{H}$ beam. Molecules of $\mathrm{H}_{2} \mathrm{CO}$ and, subsequently, $\mathrm{CH}_{3} \mathrm{OH}$ were significantly produced with consumption of $\mathrm{CO}$ below $20 \mathrm{~K}$. The sudden decrease in the reaction rates at $20 \mathrm{~K}$ is considered to have arisen from the decrease in sticking coefficient of hydrogen atoms on $\mathrm{H}_{2} \mathrm{O}$ ice rather than from the decrease in the reaction rate constant (Watanabe, Shiraki, \& Kouchi 2003). This surface-temperature dependence implies that the hydrogen atoms react with CO after adsorption and diffusion on the surface: the so-called Langmuir-Hinshelwood process. The formation of these molecules is not observed when a sample is exposed to just $\mathrm{H}_{2}$ molecules. We also carefully checked for undesirable experimental factors such as contamination by, for example, carrying out a blank test. No such effects were found (Hidaka et al. 2004). Furthermore, since reactions of $\mathrm{H}_{2}$ with $\mathrm{HCO}$ and $\mathrm{CH}_{3} \mathrm{O}$ are endothermic, we conclude that $\mathrm{H}_{2} \mathrm{CO}$ and $\mathrm{CH}_{3} \mathrm{OH}$ are produced by the successive reaction (1). The intermediates, $\mathrm{HCO}$ and $\mathrm{CH}_{3} \mathrm{O}\left(\mathrm{CH}_{2} \mathrm{OH}\right)$ radicals, were not observed, indicating the relationships among reaction rates to be $k_{1} \ll k_{2}$ and $k_{3} \ll k_{4}$.

Since the column densities of reacted CO were of the order of $10^{15}-10^{16} \mathrm{~cm}^{-2}$ over the fluence of $10^{18}$ atoms $\mathrm{cm}^{-2}$, only $1 \%$ or less of the total number of injected $\mathrm{H}$ atoms were used for the hydrogenation. A significant number of $\mathrm{H}$ atoms would be consumed by $\mathrm{H}-\mathrm{H}$ recombination to produce $\mathrm{H}_{2}$ molecules. When the atomic flux decreases, the relative 


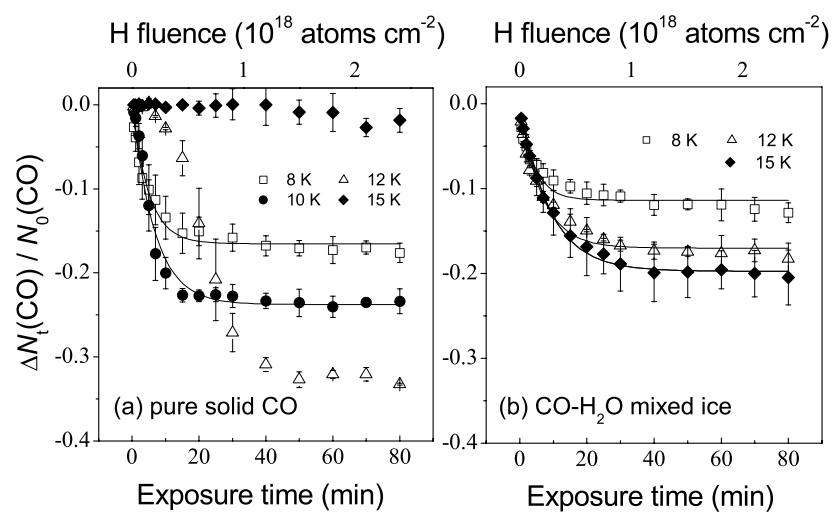

Figure 1. Attenuation of CO-column density upon $\mathrm{H}$ exposure for (a) pure solid $\mathrm{CO}$ and (b) $\mathrm{CO}-\mathrm{H}_{2} \mathrm{O}$ mixed ice. The $y$-axis is normalized to the initial column density. Solid lines are least-square fits using eq. (2).

fraction of $\mathrm{H}$ atoms used for recombination compared with those used for hydrogenation becomes smaller because the probability of $\mathrm{H}-\mathrm{H}$ recombination is proportional to the square of the surface coverage. The depletion of $\mathrm{CO}$ and the formation of $\mathrm{H}_{2} \mathrm{CO}$ and $\mathrm{CH}_{3} \mathrm{OH}$ are saturated at long exposure times. It was found that the reason for the saturation is not due to the balance with the reverse process of reaction (1) (H-atom abstraction by another $\mathrm{H}$ atom) but the limit of $\mathrm{H}$ atom diffusion in bulk (Watanabe et al. 2003, 2004). Therefore, the rates of CO decay correspond only to the rates of the first part of reaction (1), namely $\mathrm{CO}+\mathrm{H} \rightarrow \mathrm{HCO}$. We also exposed $\mathrm{CO}$ (1 eML) on $\mathrm{H}_{2} \mathrm{O}$ ice to $\mathrm{H}$ atoms. The results were essentially the same as those obtained for mixed ice.

We estimated the reaction rate constants for $\mathrm{CO}+\mathrm{H} \rightarrow \mathrm{HCO}$ using the fits of $\mathrm{CO}$ data (Figure 1) to

$$
\frac{\Delta N(\mathrm{CO})}{N_{0}(\mathrm{CO})}=\alpha\left(1-\exp \left(-k n_{\mathrm{H}} t\right)\right)
$$

and

$$
\frac{d n_{\mathrm{H}}}{d t}=P f_{\mathrm{H}}-k_{\mathrm{H}-\mathrm{H}} n_{\mathrm{H}}^{2}-k_{\mathrm{H}-\mathrm{CO}} n_{\mathrm{H}} n_{\mathrm{CO}}
$$

where $\alpha$ is a saturation value, $k$ the rate constants, $P$ sticking coefficient of atom, $f_{\mathrm{H}}$ the flux of $\mathrm{H}$ atoms, and $n_{\mathrm{H}}$ and $n_{\mathrm{CO}}$ the surface densities of $\mathrm{H}$ atoms and $\mathrm{CO}$, respectively. In equation (3), we neglect the terms for the reactions of $\mathrm{H}$ with $\mathrm{HCO}, \mathrm{H}_{2} \mathrm{CO}$, and $\mathrm{CH}_{3} \mathrm{O}$ and the desorption of $\mathrm{H}$ atoms, because the rates of $\mathrm{H}$-atom loss at the surface by those processes must be very slow. Chigai et al. (2005, in preparation) found that, under our experimental conditions, the time variation of $n_{\mathrm{H}}$ is governed by the atomic flux (the first term of right side in eq. 3) and the loss due to $\mathrm{H}-\mathrm{H}$ recombination (the second term) and $n_{\mathrm{H}}$ becomes constant immediately. By setting the left side of eq. (3) to zero, we obtained $n_{\mathrm{H}}=53.9 \times\left(f_{\mathrm{H}} P\right)^{1 / 2} \mathrm{~cm}^{-2}$. Here, the value of $k_{\mathrm{H}-\mathrm{H}}$ was estimated by using activation energy of $103 \mathrm{~K}$ (Ivliev et al. 1982) and a square potential barrier of $1-\AA$ width for the recombination. Consequently, the values of $\alpha$ and the product $k_{\mathrm{H}-\mathrm{CO}} P^{1 / 2}$ (effective rate constants) are determined by the fittings, as shown by the solid lines in Figure 1. The effective rate constants at $15 \mathrm{~K}$ are $4.7 \times 10^{-12}$ and $1.5 \times 10^{-12} \mathrm{~cm}^{2} \mathrm{~s}^{-1}$ for $\mathrm{H}+\mathrm{CO}(1 \mathrm{eML})$ on $\mathrm{H}_{2} \mathrm{O}$ and $\mathrm{H}+\mathrm{CO}-\mathrm{H}_{2} \mathrm{O}$ mixed ice, respectively.

\section{2. $\mathrm{H}+$ Pure Solid $C O$}

Recent investigations of the observed spectra of interstellar ice have revealed the presence of pure solid CO segregated from $\mathrm{H}_{2} \mathrm{O}$ ice (Teixeira et al. 1998; Pontoppidan et al. 2003). 
To simulate hydrogenation on such an ice and clarify the role of $\mathrm{H}_{2} \mathrm{O}$ ice, $10 \mathrm{ML}$ of pure solid $\mathrm{CO}$ was exposed to $\mathrm{H}$ atoms. The formation of $\mathrm{H}_{2} \mathrm{CO}$ and $\mathrm{CH}_{3} \mathrm{OH}$ and nondetection of radicals were observed again. However, as shown in Figure 1, the dependence of the reactions on temperature is stronger than that for $\mathrm{CO}-\mathrm{H}_{2} \mathrm{O}$ mixed ice. The reactions become very slow at $15 \mathrm{~K}$ and the behavior of the $\mathrm{CO}$ plot at $12 \mathrm{~K}$ is not like a single exponential decay. The smaller sticking coefficient of $\mathrm{H}$ atoms on pure solid $\mathrm{CO}$ than that on $\mathrm{H}_{2} \mathrm{O}$ ice would be responsible for these features. The sticking coefficient on $\mathrm{CO}$ may drop at around $12-15 \mathrm{~K}$. The initial stage of the CO-decay curve at $12 \mathrm{~K}$ implies that the sticking coefficient gradually increases with exposure time due to the production of $\mathrm{H}_{2} \mathrm{CO}$. The $\mathrm{H}_{2} \mathrm{CO}$ produced on $\mathrm{CO}$ would enhance the sticking coefficient. In fact, when we deposited 0.3 eML of $\mathrm{H}_{2} \mathrm{CO}$ on solid $\mathrm{CO}$ in advance and subsequently exposed it to $\mathrm{H}$ atoms at $12 \mathrm{~K}$, the shape of the $\mathrm{CO}$ decay curve became like that of a single-exponential decay curve similar to that at $10 \mathrm{~K}$ (Watanabe et al. 2004). We fitted the CO data at 8 and $10 \mathrm{~K}$ to eq. (2) and estimated the effective rate constants, which are shown in $\S 5$.

\section{3. $\mathrm{D}+\mathrm{CO}(1 \mathrm{eML})$ on $\mathrm{H}_{2} \mathrm{O}$ Ice}

In order to compare the deuteration of $\mathrm{CO}$ with the hydrogenation of $\mathrm{CO}, \mathrm{CO}$ (1 eML) on $\mathrm{H}_{2} \mathrm{O}$ was exposed to cold deuterium atoms. The flux of deuterium atoms was the same as that of hydrogen atoms for $\mathrm{H}+\mathrm{CO}(1 \mathrm{eML})$ on $\mathrm{H}_{2} \mathrm{O}$ ice. The results will be described in detail elsewhere (Hidaka, Kouchi, \& Watanabe 2005, in preparation). Briefly, the products $\mathrm{D}_{2} \mathrm{CO}$ and $\mathrm{CD}_{3} \mathrm{OD}$ were observed and the temperature dependence of $\mathrm{CO}$ decay was similar to that observed for hydrogenation. However, the formation rates of $\mathrm{D}_{2} \mathrm{CO}$ and $\mathrm{CD}_{3} \mathrm{OD}$ were much slower than those of $\mathrm{H}_{2} \mathrm{CO}$ and $\mathrm{CH}_{3} \mathrm{OH}$ for hydrogenation. Since the sticking coefficient of $\mathrm{D}$ atoms must be very similar to that of $\mathrm{H}$ atoms at the same surface temperature, this difference is considered to result from the difference in reaction rate constants. The value of $k_{\mathrm{D}} P^{1 / 2}$ at $15 \mathrm{~K}$ for $\mathrm{D}+\mathrm{CO} \rightarrow \mathrm{DCO}$ was determined by fitting, using eq. (2). The ratio of deuteration rate constant $k_{\mathrm{D}}$ to hydrogenation rate constant $k_{\mathrm{H}}, k_{\mathrm{D}} / k_{\mathrm{H}}$, is approximately 0.1 at $15 \mathrm{~K}$. This isotope effect is ascribed to the mass effect of the tunneling reaction.

\section{4. $\mathrm{H}+\mathrm{H}_{2} \mathrm{CO}(1 \mathrm{eML})$ on $\mathrm{H}_{2} \mathrm{O}$ Ice}

In order to estimate the reaction rates for the hydrogenation of $\mathrm{H}_{2} \mathrm{CO}$ directly from the decay of $\mathrm{H}_{2} \mathrm{CO}$, solid $\mathrm{H}_{2} \mathrm{CO}$ ( 1 eML) was produced on $\mathrm{H}_{2} \mathrm{O}$ ice and exposed to cold $\mathrm{H}$ atoms. $\mathrm{CH}_{3} \mathrm{OH}$ was gradually produced with the consumption of $\mathrm{H}_{2} \mathrm{CO}$. We confirmed that $\mathrm{H}_{2} \mathrm{CO}$ does not react with $\mathrm{H}_{2}$. The reaction rate constant $k$ at $15 \mathrm{~K}$ relative to that for $\mathrm{CO}$ hydrogenation on $\mathrm{H}_{2} \mathrm{O}$ ice was obtained by the fitting of $\mathrm{H}_{2} \mathrm{CO}$ decay curve to be approximately 0.5 on the assumption that the sticking coefficients are the same because atoms mainly adsorb first on $\mathrm{H}_{2} \mathrm{O}$ ice which is a main component at the surface (Hidaka et al. 2004).

\section{5. $\mathrm{H}+\mathrm{D}(\mathrm{D} / \mathrm{H \sim 0.1})+$ Pure Solid $\mathrm{CO}(10 \mathrm{ML})$ and $\mathrm{D}+\mathrm{Solid} \mathrm{CH}_{3} \mathrm{OH}(4 \mathrm{ML})$}

To simulate the formation of deuterated formaldehyde and methanol on grains, pure solid $\mathrm{CO}$ was exposed to $\mathrm{H}$ and $\mathrm{D}$ atoms simultaneously at an atomic flux ratio of $\mathrm{D} / \mathrm{H} \sim 0.1$, at which accretion of atoms can be achieved in the gas phase (Roberts et al. 2003). Variations in IR spectra observed upon $\mathrm{H}$ and $\mathrm{D}$ exposure are shown in Figure 2. Peaks corresponding to the products of $\mathrm{H}_{2} \mathrm{CO}\left(1729,1499,1247\right.$, and $\left.1177 \mathrm{~cm}^{-1}\right)$, HDCO (1700 and $\left.1401 \mathrm{~cm}^{-1}\right), \mathrm{D}_{2} \mathrm{CO}\left(1684 \mathrm{~cm}^{-1}\right), \mathrm{CH}_{3} \mathrm{OH}\left(1039\right.$ and $\left.1126 \mathrm{~cm}^{-1}\right), \mathrm{CH}_{2} \mathrm{DOH}(1330$, 1290, and $\left.1047 \mathrm{~cm}^{-1}\right), \mathrm{CHD}_{2} \mathrm{OH}\left(1331,1301,1091\right.$, and $\left.950 \mathrm{~cm}^{-1}\right)$, and $\mathrm{CD}_{3} \mathrm{OH}(1128$ and $982 \mathrm{~cm}^{-1}$ ) are clearly observed. Radicals and Me-OD (Me; methyl group) were not detected. This seems to be consistent with the low abundance of Me-OD observed in 


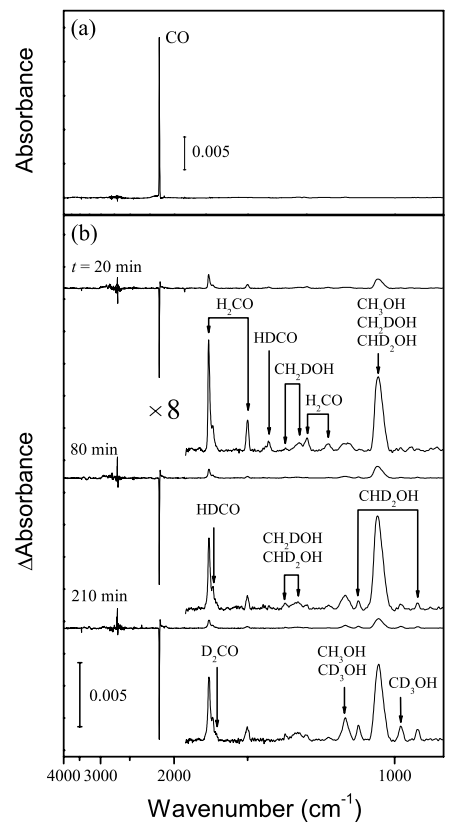

Figure 2. Variation in infrared absorption spectra for simultaneous exposure of solid $\mathrm{CO}$ to $\mathrm{H}$ and $\mathrm{D}$ atoms at $10 \mathrm{~K} .(a)$ Initial spectrum prior to exposure. (b) Spectra obtained by subtraction of the initial one from those obtained after the exposure time $t$.

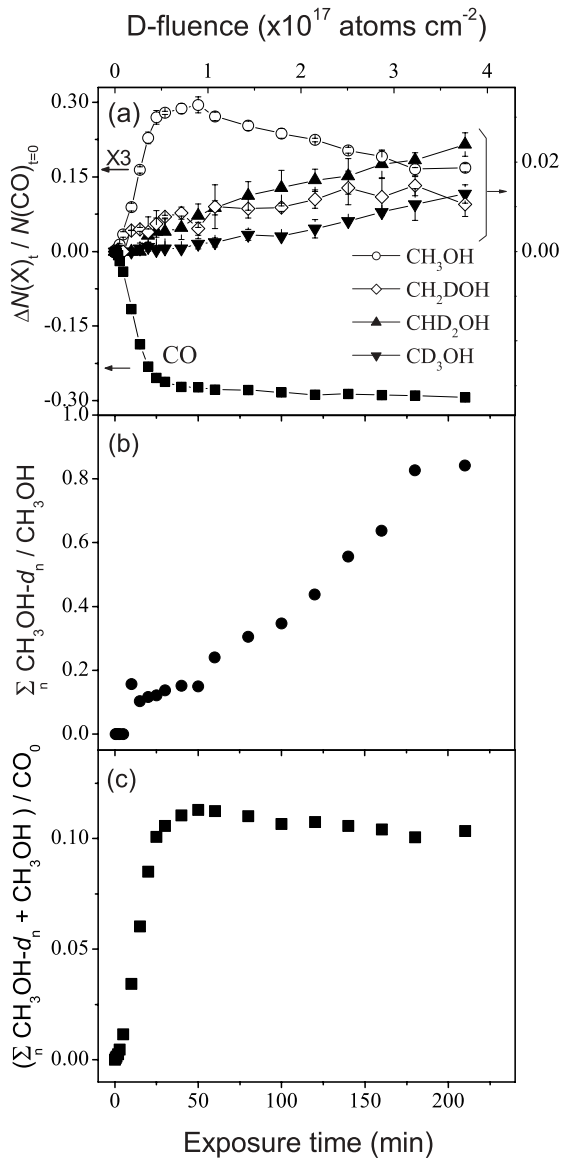

Figure 3. Variation in column densities as a function of exposure time and D fluence. (a) column densities for $\mathrm{CO}$ and methanol- $d_{\mathrm{n}}$. The y-axis is normalized to the initial column density of CO. Note that the left and right $\mathrm{y}$-axes correspond to $\mathrm{CO}$ and normal methanol, and methanol- $d_{\mathrm{n}}$, respectively. (b) Sum of column densities of methanol- $d_{n}$ relative to column density of $\mathrm{CH}_{3} \mathrm{OH}$. (c) Sum of column densities for methanol- $d_{\mathrm{n}}$ and $\mathrm{CH}_{3} \mathrm{OH}$.

molecular clouds (Parise et al. 2004). The variation in column densities for parent CO, $\mathrm{CH}_{3} \mathrm{OH}$, and deuterated methanol and the sum of column densities of methanol- $d_{\mathrm{n}}$ are plotted in

Figure 3(a) and (b), respectively. Figure 3(c) shows a plot of the sum of the column densities for $\mathrm{CH}_{3} \mathrm{OH}$ and methanol- $d_{\mathrm{n}}$ normalized to the initial column density of $\mathrm{CO}$. Here, we concentrate on the formation of methanol- $d_{\mathrm{n}}$ and thus do not show the variation in column densities for formaldehyde. From Figure 3(b), one can see that deuterium fractionation progresses with exposure time. By examining Figure 3(a), information on the formation process of methanol- $d_{\mathrm{n}}$ is obtained. The yield of $\mathrm{CH}_{3} \mathrm{OH}$ first increased quickly and subsequently reached a maximum. $\mathrm{CH}_{2} \mathrm{DOH}, \mathrm{CHD}_{2} \mathrm{OH}$, and $\mathrm{CD}_{3} \mathrm{OH}$ were 


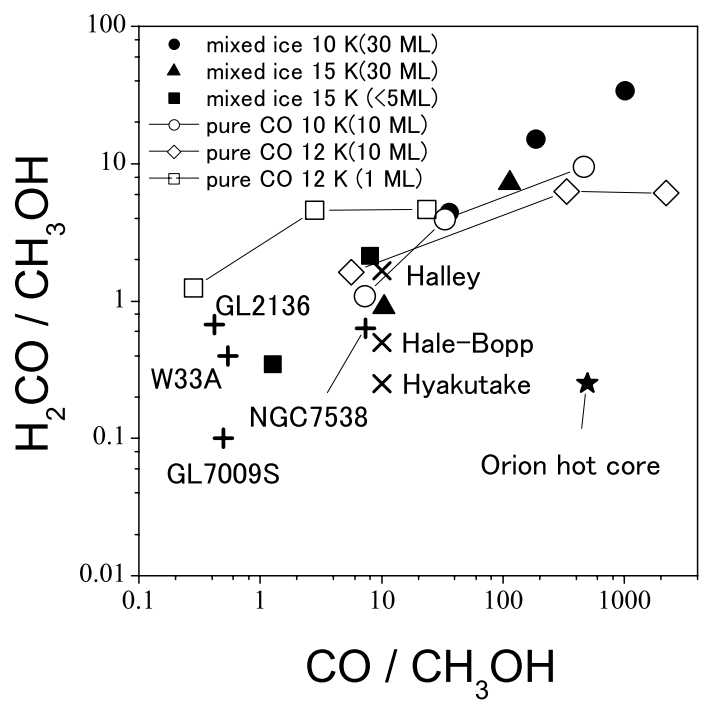

Figure 4. Column density ratios of $\mathrm{H}_{2} \mathrm{CO}$ and $\mathrm{CO}$ relative to $\mathrm{CH}_{3} \mathrm{OH}$ for the experimental and observational results. Open symbols represent results for pure solid CO, solid symbols indicate mixed-ice results, and observations are denoted by + for interstellar ice (Kean et al. 2002), $\times$ for comets, and $\star$ for the Orion compact ridge (Ehrenfreund \& Charnley 2000).

produced in sequence with decreasing amount of $\mathrm{CH}_{3} \mathrm{OH}$. These features cannot be explained by the successive addition of $\mathrm{H}$ and $\mathrm{D}$ to $\mathrm{CO}$ but indicate the occurrence of $\mathrm{H}-\mathrm{D}$ substitution in methanol after the formation of $\mathrm{CH}_{3} \mathrm{OH}$. In Figure 3(c), the sum of $\mathrm{CH}_{3} \mathrm{OH}$ and total deuterated methanol becomes constant after the exposure of 25 min, indicating that H-D substitution in methanol is dominant after that period of time; successive addition and substitution compete until then. As described in the next section, addition of $\mathrm{D}$ atoms to formaldehyde $\left(-d_{\mathrm{n}}\right)$ is very slow. Therefore, substitution would be dominant for the formation of methanol- $d_{\mathrm{n}}$ even before $25 \mathrm{~min}$.

To confirm whether $\mathrm{H}-\mathrm{D}$ substitution in methanol occurs, solid $\mathrm{CH}_{3} \mathrm{OH}$ was exposed to $\mathrm{D}$ atoms only. The yields of $\mathrm{CH}_{2} \mathrm{DOH}, \mathrm{CHD}_{2} \mathrm{OH}$, and $\mathrm{CD}_{3} \mathrm{OH}$ were obtained with the consumption of $\mathrm{CH}_{3} \mathrm{OH}$. The time variation of column densities again clearly reveals successive H-D substitution in methanol (see Fig. 4 in Nagaoka, Watanabe, \& Kouchi 2005). When parent solids of $\mathrm{CH}_{3} \mathrm{OD}, \mathrm{CD}_{3} \mathrm{OH}, \mathrm{CHD}_{2} \mathrm{OH}, \mathrm{CH}_{2} \mathrm{DOH}$, and $\mathrm{CD}_{3} \mathrm{OD}$ were exposed to $\mathrm{H}$ atoms, no reaction was observed. That is, once deuterated methanol (methanol- $d_{\mathrm{n}}$ ) is produced, it never returns to its predeuterated state (methanol- $d_{n-1}$ ) by reaction with $\mathrm{H}$ atoms. Therefore, H-D substitution in methanol on the grain surface can act as the process of deuterium fractionation and thus should be included in the theoretical models. A detailed discussion of this is described elsewhere (Nagaoka et al. 2005).

\section{6. $\mathrm{D}+$ Solid $\mathrm{H}_{2} \mathrm{CO}$ and $\mathrm{H}+$ Solid $\mathrm{D}_{2} \mathrm{CO}$}

The substitution reactions in formaldehyde were also investigated. Detailed results will be reported elsewhere (Watanabe, Hidaka, \& Kouchi 2005, in preparation). Briefly, for D + solid $\mathrm{H}_{2} \mathrm{CO}$, although there is competition between $\mathrm{H}-\mathrm{D}$ substitution in formaldehyde producing $\mathrm{HDCO}$ and $\mathrm{D}_{2} \mathrm{CO}$ and the addition of $\mathrm{D}$ atoms leading to deuterated methanol, the dominant process is the evolution of $\mathrm{H}_{2} \mathrm{CO} \rightarrow \mathrm{HDCO} \rightarrow \mathrm{D}_{2} \mathrm{CO}$ by substitution. It is not clear in the present work whether the substitution proceeds via the sequence of $\mathrm{H}$ abstraction and $\mathrm{D}$ addition or via $\mathrm{H}-\mathrm{D}$ direct exchange. The yields of $\mathrm{CD}_{3} \mathrm{OD}$ and the other deuterated methanol were small even at the $\mathrm{D}$ fluence of $\sim 10^{18} \mathrm{~cm}^{-2}$, indicating that the additions of $\mathrm{D}$ to $\mathrm{D}_{2} \mathrm{CO}, \mathrm{HDCO}$ and $\mathrm{H}_{2} \mathrm{CO}$ are slower than substitution. $\mathrm{H}-\mathrm{D}$ substitution in $\mathrm{H}_{2} \mathrm{CO}$ would be an important process to produce deuterated formaldehyde in molecular clouds as much as successive $\mathrm{H} / \mathrm{D}$ addition to $\mathrm{CO}$. 
For $\mathrm{H}+$ solid $\mathrm{D}_{2} \mathrm{CO}$, the substitution reaction by $\mathrm{H}$ atom $\left(\mathrm{D}_{2} \mathrm{CO} \rightarrow \mathrm{HDCO} \rightarrow \mathrm{H}_{2} \mathrm{CO}\right)$ proceeded significantly unlike the case of $\mathrm{H}+$ solid methanol- $d_{\mathrm{n}}$. The yield of $\mathrm{CHD}_{2} \mathrm{OH}$ produced by successive $\mathrm{H}$ addition to $\mathrm{D}_{2} \mathrm{CO}$ is comparable to that of $\mathrm{CH}_{3} \mathrm{OH}$ produced through the route of $\mathrm{D}_{2} \mathrm{CO} \rightarrow \mathrm{HDCO} \rightarrow \mathrm{H}_{2} \mathrm{CO} \rightarrow \mathrm{CH}_{3} \mathrm{OH}$ (D-H substitution and subsequent $\mathrm{H}$ addition) throughout most of the exposure time. This implies that the rate of $\mathrm{H}$ addition to $\mathrm{D}_{2} \mathrm{CO}$ is similar to that of $\mathrm{D}-\mathrm{H}$ substitution (reduction of deuteration level) in $\mathrm{D}_{2} \mathrm{CO}$. The $\mathrm{D}-\mathrm{H}$ substitution must proceed via sequence of $\mathrm{D}$ abstraction and $\mathrm{H}$ addition because $\mathrm{D}-\mathrm{H}$ direct exchange in formaldehyde $\left(-d_{\mathrm{n}}\right)$ is endothermic.

\section{7. $\mathrm{D}+$ Solid $\mathrm{CD}_{3} \mathrm{OH}, \mathrm{CHD}_{2} \mathrm{OH}$, and $\mathrm{CH}_{2} \mathrm{DOH}$}

To determine the relative rates of $\mathrm{H}-\mathrm{D}$ substitution in methanol- $d_{n}$, solid $\mathrm{CH}_{3} \mathrm{OH}$, $\mathrm{CH}_{2} \mathrm{DOH}$, and $\mathrm{CHD}_{2} \mathrm{OH}$ were exposed to $\mathrm{D}$ atoms independently (Nagaoka, Watanabe, \& Kouchi 2005, in preparation). Briefly, from the decay curves of parent solids, the relative rates were estimated to be 4,2 , and 1 for $\mathrm{CH}_{3} \mathrm{OH} \rightarrow \mathrm{CH}_{2} \mathrm{DOH}, \mathrm{CH}_{2} \mathrm{DOH} \rightarrow$ $\mathrm{CHD}_{2} \mathrm{OH}$, and $\mathrm{CHD}_{2} \mathrm{OH} \rightarrow \mathrm{CD}_{3} \mathrm{OH}$, respectively. The number of $\mathrm{H}$ atoms on the methyl side would govern the reactivity.

\section{Implications for Astrochemistry}

A comparison of the experimental results obtained for $\mathrm{H}+$ pure solid $\mathrm{CO}$ and $\mathrm{CO}-\mathrm{H}_{2} \mathrm{O}$ mixed ice with the observational results for molecular clouds is attempted in $\S 4.1$. The potential contribution of the surface reactions of $\mathrm{D}$ atoms to the formation of deuterated formaldehyde and methanol is discussed in $\S 4.2$.

\section{1. $\mathrm{H}_{2} \mathrm{CO}$ and $\mathrm{CH}_{3} \mathrm{OH}$}

We compare our results for the hydrogenation of $\mathrm{CO}-\mathrm{H}_{2} \mathrm{O}$ mixed ice and pure solid $\mathrm{CO}$ with the observational results. For instance, assuming that the number density of hydrogen atoms is $1 \mathrm{~cm}^{-3}$ and the temperature of the atoms is the same as that of grains in a molecular cloud, the fluences for $10 \mathrm{~K}$ are $1.3 \times 10^{16}, 1.3 \times 10^{17}$, and $1.3 \times 10^{18} \mathrm{~cm}^{-2}$ over $10^{4}, 10^{5}$, and $10^{6} \mathrm{yrs}$, respectively. In the present experiments, those fluences approximately correspond to 1,4 , and 40 minutes, respectively, at $10 \mathrm{~K}$. The obtained ratios of $\mathrm{CO} / \mathrm{CH}_{3} \mathrm{OH}$ and $\mathrm{H}_{2} \mathrm{CO} / \mathrm{CH}_{3} \mathrm{OH}$ are plotted in Figure 4 with the observational abundances. The plots vary from left to right with the decrease in $\mathrm{H}$ fluence from $10^{6}$ to $10^{4}$ yrs. The leftmost plots correspond to $10^{6}$ yrs. The results for the higher fluences $\left(10^{6}\right.$ yrs $)$ are reasonably consistent with the observations of molecular clouds and comets. For pure $\mathrm{CO}$, the data at $12 \mathrm{~K}$ is closest to the observations, while the $15 \mathrm{~K}$ results are closest for the mixed ice. For both, thinner ice produces higher abundances of $\mathrm{CH}_{3} \mathrm{OH}$ relative to the amounts of $\mathrm{CO}$ and $\mathrm{H}_{2} \mathrm{CO}$. For thinner ice, the fraction of reactive $\mathrm{CO}$ exposed on the surface relative to the fraction of unreactive $\mathrm{CO}$ buried in bulk is larger and thus, a ratio of $\mathrm{CO} / \mathrm{CH}_{3} \mathrm{OH}$ lower than that of thick ice is achieved. The ratio of $\mathrm{H}_{2} \mathrm{CO} / \mathrm{CH}_{3} \mathrm{OH}$ for pure $\mathrm{CO}$ tends to be larger than that for mixed ice at lower ratios of $\mathrm{CO} / \mathrm{CH}_{3} \mathrm{OH}$, and this tendency becomes stronger for thinner ice. This feature can be explained by an onion-like structure, as described below. When CO molecules are deposited on the surface, the $\mathrm{CO}$ molecules can readily aggregate into bulk (solid) $\mathrm{CO}$ even below 1 eML coverage. However, once $\mathrm{H}_{2} \mathrm{CO}$ layers have been produced on the solid $\mathrm{CO}$, only the upper layer of the $\mathrm{H}_{2} \mathrm{CO}$ can be converted to $\mathrm{CH}_{3} \mathrm{OH}$, resulting in a significant fraction of remnant $\mathrm{H}_{2} \mathrm{CO}$ in the bulk. That is, solid $\mathrm{CO}$ finally becomes a CO- $\mathrm{H}_{2} \mathrm{CO}-\mathrm{CH}_{3} \mathrm{OH}$ trilayer structure (Watanabe et al. 2004). In the case of mixed ice, $\mathrm{CO}$ molecules tend to be isolated in cracks or boundaries of $\mathrm{H}_{2} \mathrm{O}$ ice and most of the $\mathrm{CO}$ molecules can be finally converted to $\mathrm{CH}_{3} \mathrm{OH}$. The experimental conditions realized 
for thinner ice may simulate higher $\mathrm{H} / \mathrm{CO}$ ratios of accretion onto grains in molecular clouds, where $\mathrm{CO}$ always has a chance to react with accreted $\mathrm{H}$ atoms at the surface before being buried in bulk.

Our results reveal that the hydrogenation of $\mathrm{CO}$ on the grains in a dense core is efficient for the production of $\mathrm{H}_{2} \mathrm{CO}$ and $\mathrm{CH}_{3} \mathrm{OH}$ regardless of the type of mantle - pure solid $\mathrm{CO}$ (apolar ice) or $\mathrm{CO}-\mathrm{H}_{2} \mathrm{O}$ mixed (polar) ice - as long as the abundance of $\mathrm{CO}$ is significant. When $\mathrm{CO}$ is abundant in the ice, the competition of $\mathrm{H}$-atom reactions with less abundant species like $\mathrm{C}_{2} \mathrm{H}_{2}$ and $\mathrm{C}_{2} \mathrm{H}_{4}$ has little effect on the hydrogenation of $\mathrm{CO}$.

It should be noted that the efficiency of the hydrogenation of CO is strongly dependent on the flux of $\mathrm{H}$ atoms; in other words, the number density and kinetic temperature of $\mathrm{H}$ atoms and the temperature of the grain. Furthermore, when the photon field of molecular clouds becomes strong, the contribution of photoinduced reactions should be considered. Strictly speaking, these factors should be taken into account.

\section{2. $\mathrm{H}_{2} \mathrm{CO}-\mathrm{d}_{n}$ and $\mathrm{CH}_{3} \mathrm{OH}-\mathrm{d}_{n}$}

Assuming an $\mathrm{H}$ number density of $1 \mathrm{~cm}^{-3}$, an atomic $\mathrm{D} / \mathrm{H}$ ratio of 0.1 in the accreting gas, and that the kinetic temperature of the atoms is the same as that of the grain, the $\mathrm{D}(\mathrm{H})$ atom fluences in a $10 \mathrm{~K}$ molecular cloud will be $1.3 \times 10^{16}\left(1.3 \times 10^{17}\right)$, $6.5 \times 10^{16}\left(6.5 \times 10^{17}\right)$, and $1.3 \times 10^{17}\left(1.3 \times 10^{18}\right) \mathrm{cm}^{-2}$ over $10^{5}, 5 \times 10^{5}$, and $10^{6} \mathrm{yrs}$, respectively. In the experiment on $\mathrm{H}+\mathrm{D}+$ solid $\mathrm{CO}$, these fluences approximately correspond to exposure times of 10,35 , and $70 \mathrm{~min}$, respectively. The ratios of deuterated methanol to the amount of remaining $\mathrm{CH}_{3} \mathrm{OH}$, denoted in the form $\left(\mathrm{CH}_{2} \mathrm{DOH} / \mathrm{CH}_{3} \mathrm{OH}\right.$, $\left.\mathrm{CHD}_{2} \mathrm{OH} / \mathrm{CH}_{3} \mathrm{OH}, \mathrm{CD}_{3} \mathrm{OH} / \mathrm{CH}_{3} \mathrm{OH}\right)$, after exposure times of 10,35 , and $70 \mathrm{~min}$ are $(0.16,0,0),(0.09,0.05,0.01)$ and $(0.11,0.13,0.03)$, respectively. These values are markedly consistent with the observations (Parise et al. 2004) of $(0.3 \pm 0.2,0.06 \pm 0.05$, $0.014 \pm 0.014)$, indicating that observed deuterium fractionation can be achieved by grainsurface reactions once the atomic $\mathrm{D} / \mathrm{H}$ ratio of 0.1 in the accretion gas is obtained as suggested by the models. The nondetection of $\mathrm{Me}-\mathrm{OD}$ is consistent with the low abundance of $\mathrm{Me}-\mathrm{OD}$ observed toward a low-mass protostar. For formaldehyde, our obtained raios of $\left(\mathrm{HDCO} / \mathrm{H}_{2} \mathrm{CO}, \mathrm{D}_{2} \mathrm{CO} / \mathrm{H}_{2} \mathrm{CO}\right)$ are $(0.44,0.034)$ which are also consistent with the observation of $(0.14,0.05)$ (Loinard et al. 2000). We also performed an experiment with a $\mathrm{D} / \mathrm{H}$ ratio of 0.05 and found that the results were very similar to those obtained for the ratio of 0.1 .

\section{Surface Reaction Network for Formaldehyde and Methanol}

To date, we have investigated the reactions of hydrogenation, deuteration, and substitution for the systems of solid CO, formaldehyde, and methanol. In Figure 5, a diagram of the surface reaction network for $\mathrm{CO}$, formaldehyde, and methanol is shown with the relative reaction rates estimated so far. Generally speaking, hydrogen addition occurs at a faster rate than deuterium addition due to the effect of the tunneling reaction. The rate constants of hydrogenation and deuteration of $\mathrm{CO}$ are higher than those of $\mathrm{H}_{2} \mathrm{CO}$ and $\mathrm{D}_{2} \mathrm{CO}$, respectively. An important finding is that the reaction rates strongly depend on not only the surface temperature but also on the composition and structure of the surface. For instance, the hydrogenation rate of pure solid $\mathrm{CO}$ is different from that of $\mathrm{CO}$ in $\mathrm{H}_{2} \mathrm{O}$ ice, and $\mathrm{H}_{2} \mathrm{CO}$ on solid $\mathrm{CO}$ enhances the hydrogenation of $\mathrm{CO}$ (Watanabe et al. 2005). $\mathrm{H}-\mathrm{D}$ substitution proceeds for both formaldehyde $\left(\mathrm{H}_{2} \mathrm{CO}-d_{n} \stackrel{\mathrm{D}}{\longrightarrow} \mathrm{H}_{2} \mathrm{CO}-d_{\mathrm{n}+1} ; \mathrm{n}=0-1\right)$ and methanol $\left(\mathrm{CH}_{3} \mathrm{OH}-d_{\mathrm{n}} \stackrel{\mathrm{D}}{\longrightarrow} \mathrm{CH}_{3} \mathrm{OH}-d_{\mathrm{n}+1} ; \mathrm{n}=0-2\right)$. There are two possible elementary processes for $\mathrm{H}-\mathrm{D}$ substitution: direct $\mathrm{H}-\mathrm{D}$ exchange (e.g., $\mathrm{CH}_{3} \mathrm{OH}+\mathrm{D} \rightarrow \mathrm{CH}_{2} \mathrm{DOH}+$ 


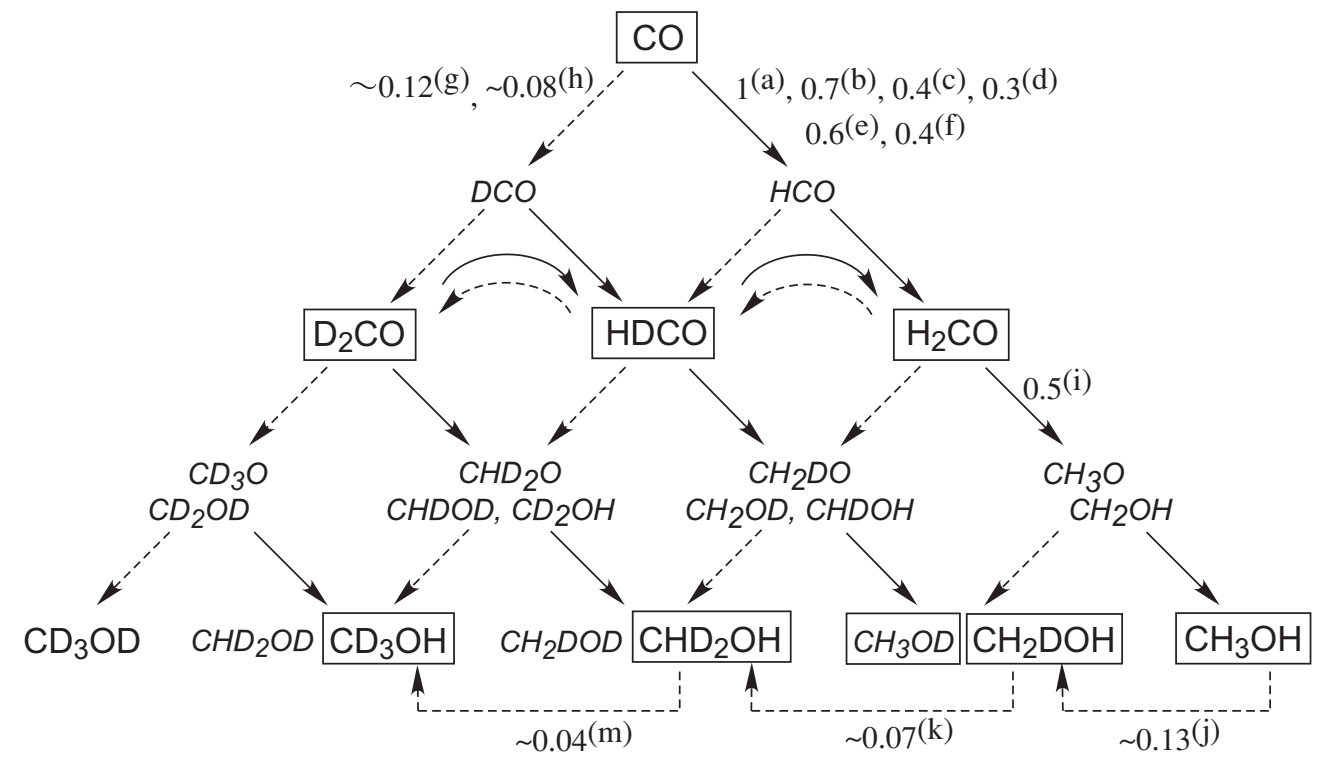

Figure 5. Surface reaction network for CO, formaldehyde, and methanol. Block and italic letters are used to denote products that were detected and not detected in the experiments, respectively. Square frames denote molecules that have been observed in molecular clouds. Solid and dashed arrows represent reactions of $\mathrm{H}$ and $\mathrm{D}$ atoms, respectively. Although it is likely that abstraction reactions proceed, they are not shown. The values shown are effective rate constants relative to that for $\mathrm{H}+\mathrm{CO}(1 \mathrm{eML})$ on $\mathrm{H}_{2} \mathrm{O}$ (see text) estimated experimentally for the processes represented by the arrows. It should be noted that the effective rate constant strongly depends on the surface composition, structure, and temperature. The values were determined from experiments: (a) $\mathrm{H}+\mathrm{CO}(1 \mathrm{eML})$ on $\mathrm{H}_{2} \mathrm{O}$ at $15 \mathrm{~K}$; (b)-(d) $\mathrm{H}+\mathrm{CO}-\mathrm{H}_{2} \mathrm{O}$ mixed ice at 8,12 , and $15 \mathrm{~K}$, respectively; (e), (f) $\mathrm{H}+$ pure $\mathrm{CO}$ at 8 and $10 \mathrm{~K}$, respectively; (g) $\mathrm{D}+\mathrm{CO}$ ( $1 \mathrm{eML}$ ) on $\mathrm{H}_{2} \mathrm{O}$ at $15 \mathrm{~K}$; (h) $\mathrm{D}+$ pure $\mathrm{CO}$ at $10 \mathrm{~K}$. (i) $\mathrm{H}+\mathrm{H}_{2} \mathrm{CO}(1 \mathrm{eML})$ on $\mathrm{H}_{2} \mathrm{O}$ at $15 \mathrm{~K}$; (j) D + pure solid $\mathrm{CH}_{3} \mathrm{OH}(20 \mathrm{ML})$ at $10 \mathrm{~K} ;(\mathrm{k}) \mathrm{D}+$ pure solid $\mathrm{CH}_{2} \mathrm{DOH}(20 \mathrm{ML})$ at $10 \mathrm{~K}$; and $(\mathrm{m}) \mathrm{D}+$ pure solid $\mathrm{CHD}_{2} \mathrm{OH}(20 \mathrm{ML})$ at $10 \mathrm{~K}$.

$\mathrm{H}$ ) and the sequence of atomic abstraction and addition (e.g., $\mathrm{CH}_{3} \mathrm{OH}+\mathrm{D} \rightarrow \mathrm{CH}_{2} \mathrm{OH}+$ $\mathrm{HD}$ and subsequently $\mathrm{CH}_{2} \mathrm{OH}+\mathrm{D} \rightarrow \mathrm{CH}_{2} \mathrm{DOH}$ ). Although it is not clear which process, the direct exchange or the abstraction-addition, was dominant in our experiments, the activation energies for the latter process is lower than those for the former one (Blowers, Ford, \& Masel 1998). For the latter case, H-abstraction/D-addition, the nondetection of $\mathrm{Me}-\mathrm{OD}$ in the present experiments would be reasonable because $\mathrm{H}$-abstraction in the methyl-side by either $\mathrm{H}$ or $\mathrm{D}$ has a much lower barrier than in $-\mathrm{OH}$ (Kerkeni \& Clary 2004).

In contrast, D-H substitution proceeds in formaldehyde $\left(\mathrm{H}_{2} \mathrm{CO}-d_{\mathrm{n}+1} \stackrel{\mathrm{H}}{\longrightarrow} \mathrm{H}_{2} \mathrm{CO}-d_{\mathrm{n}}\right)$ proceeds, while that in methanol $\left(\mathrm{CH}_{3} \mathrm{OH}-d_{n+1} \stackrel{\mathrm{H}}{\longrightarrow} \mathrm{CH}_{3} \mathrm{OH}-d_{\mathrm{n}}\right)$ was not observed. For formaldehyde, since the direct $\mathrm{D}-\mathrm{H}$ exchange (e.g., $\mathrm{D}_{2} \mathrm{CO}+\mathrm{H} \rightarrow \mathrm{HDCO}+\mathrm{D}$ ) is endothermic, the combination of $\mathrm{D}$-atom abstraction and $\mathrm{H}$-atom addition is responsible for D-H substitution. For methanol, the direct D-H exchange is also endothermic and, furthermore, an ab-initio calculation by Lendvay et al. (1997) indicates that the reaction of $\mathrm{H}$-abstraction by $\mathrm{H}$ atoms from $\mathrm{CH}_{3} \mathrm{OH}-d_{\mathrm{n}}$ (e.g., $\mathrm{CH}_{2} \mathrm{DOH}+\mathrm{H} \rightarrow \mathrm{CHDOH}+\mathrm{H}_{2}$ ) is much faster than that for D-abstraction by $\mathrm{H}$ atoms from $\mathrm{CH}_{3} \mathrm{OH}-d_{\mathrm{n}}$ (e.g., $\mathrm{CH}_{2} \mathrm{DOH}+$ $\mathrm{H} \rightarrow \mathrm{CH}_{2} \mathrm{OH}+\mathrm{HD}$ ). This would be the reason why D-H substitution was not observed. 


\section{Summary}

We have revealed that the hydrogenation of solid $\mathrm{CO}$ on grain surfaces can be a major process in the production of $\mathrm{H}_{2} \mathrm{CO}$ and $\mathrm{CH}_{3} \mathrm{OH}$ in the dense core of molecular clouds where the photon field is very weak. The hydrogenation rates strongly depend on not only the surface temperature but also the composition of the surface. Hydrogenation of $\mathrm{CO}$ at $12 \mathrm{~K}$ and above is found to be promoted by the coexistence of $\mathrm{H}_{2} \mathrm{CO}$ and $\mathrm{H}_{2} \mathrm{O}$ molecules on the surface.

The measurements of the deuterium atom exposure of solid CO, formaldehyde, and methanol demonstrated for the first time that deuteration of $\mathrm{CO}$ is much slower than hydrogenation of $\mathrm{CO}$ and that $\mathrm{H}-\mathrm{D}$ substitution in solid methanol (methyl side) occurs and acts as a channel for the deuterium fractionation of methanol observed in molecular clouds.

Several effective rate constants for hydrogenation, deuteration, and H-D substitution have been determined to construct the surface reaction network for $\mathrm{CO}, \mathrm{H}_{2} \mathrm{CO}, \mathrm{H}_{2} \mathrm{CO}-d_{\mathrm{n}}$, $\mathrm{CH}_{3} \mathrm{OH}$, and $\mathrm{CH}_{3} \mathrm{OH}-d_{\mathrm{n}}$.

\section{References}

Allamandola, L.J., Sandford, S.A., \& Valero, G.J. 1988, Icarus 76, 225

Blowers, P., Ford, L., \& Masel, R. 1998, J. Phys. Chem. A 102, 9267

Boogert, A. C. A. \& Ehrenfreund, P. 2004, in Astrophysics of Dust, eds. A.N. Witt, G.C. Clayton, \& B.T. Draine (APS Conference Series), Vol. 309, p. 547

Crovisier, J. \& Bockelée-Morvan, D. 1999, Space Sci. Rev. 90, 19

Crovisier, J. et al. 2004, A\&\&A 418, 1141

Ehrenfreund, P. \& Charnley, S.B. 2000, ARAA 38, 427

Hidaka, H., Watanabe, N., Shiraki, T., Nagaoka, A., \& Kouchi, 2004, Ap. J. 614, 1124

Hiraoka, K., Ohashi, N., Kihara, Y., Yamamoto, K., Sato, T., \& Yamashita, A. 1994, Chem. Phys. Lett. 229, 408

Hiraoka, K., Sato, T., Sato, S., Sogoshi, N., Yokoyama, T., Takashima, H., \& Kitagawa, S. 2004, Ap. J. 577,265

Ivliev, A. V. et al. 1982, JETP Lett. 36, 472

Hudson, R.L. \& Moore, M.H. 1999, Icarus 140, 451

Kerkeni, B. \& Clary, D. C. 2004, J. Phys. Chem. A 108, 8966

Keane, J.V., Tielens, A.G.G.M., Boogert, A.C.A., Schutte, W.A., \& Whittet, D.C.B. 2001, A\&A 376,254

Lendvay, G., Bérces, T., \& Márta, F 1997, J. Phys. Chem. A 101, 1588

Loinard, L. et al. 2000, A\&A 359,1169

Nagaoka, A., Watanabe, N., \& Kouchi, A. 2005, Ap. J. 624, L265

Parise, B. et al. 2003, A\&A 410, 897

Parise, B. et al. 2004, A\&A 416, 159

Pontoppidan, K. M., Fraser, H. J., Dartois, E., Thi, W.-F., van Dishoeck, E.F., Boogert, A.C.A., d'Hendecourt, L., Tielens, A.G.G.M., \& Bisschop, S.E. 2003, A $\mathscr{G} A$ 408, 981

Roberts, H., Herbst, E., \& Millar, T.J. 2003, Ap. J. 591, L41

Schutte, W.A., Gerakines, P.A., Geballe, T.R., van Dishoeck, E.F., \& Greenberg, J.M. 1996, A $\mathscr{E} A$ 309, 633

Shalabiea, O.M. \& Greenberg, J.M. 1994, A\&A 290, 266

Teixeira, T.C, Emerson, J.P., \& Palumbo, M.E. 1998, A\&A 330, 711

Tielens, A.G.G.M. \& Allamandola, L.J. 1987, in Interstellar Processes, eds. D. Hollenbach \& H. Thronson (Kluwer, Dordrecht), p. 397

Tielens, A.G.G.M. \& Whittet, D.C.B. 1997, in Molecules in Astrophysics: Probes 8 Processes, ed. E.F. van Dishoeck (Kluwer, Dordrecht), p. 45

Walraven J.T.M. \& Silvera, I.F. 1982, Rev. Sci. Instrum. 53, 1167

Watanabe, N. \& Kouchi, A. 2002, Ap. J. 571, L173 
Watanabe, N., Shiraki, T., \& Kouchi, A. 2003, Ap. J. 588, L121

Watanabe, N., Nagaoka, A., Shiraki, T., \& Kouchi, A. 2004, Ap. J. 616, 638

Watanabe, N., Nagaoka, A., Hidaka, H., Shiraki, T., Chigai, T., \& Kouchi, A. 2005, Planet. Space Sci., submitted

\section{Discussion}

CASELLI: During the experiment, when methanol and deuterated methanol form, is there any evidence of evaporation of a fraction of the formed molecules? This is very important because even a small fraction may solve the problem of methanol formation in the gas phase of dark cold clouds.

WATANABE: I agree about the importance of desorption during the reactions. Unfortunately, we did not measure the desorbed molecules. We can say that more than $90 \%$ of the yields remain on the surface, but we do not have clear evidence of desorption in the present experiment. Measurements of desorption caused by reaction will be studied in the future after the modification of our apparatus.

HERBST: What is the fraction of product $\mathrm{CH}_{3} \mathrm{OH}$ and $\mathrm{CH}_{3} \mathrm{OD}$ that might escape into the gas in your experiments?

WATANABE: We could not detect the $\mathrm{CH}_{3} \mathrm{OD}$ product in our experiment on the exposure of solid $\mathrm{CH}_{3} \mathrm{OH}$ to $\mathrm{D}$ atoms at $10 \mathrm{~K}$. It would be under the detection limit. Activation energies for the abstraction of $\mathrm{H}$ atom from the $-\mathrm{OH}$ side by either $\mathrm{H}$ and $\mathrm{D}$ atoms are much higher than those from methyl group (Kerkeni and Clary 2004). Therefore, the production rates of methyl-OD must be much slower. For desorption, we did not measure the desorbed molecules. So, we do not have direct evidence of the desorption during reactions. Measurements of infrared absorption spectra tell us that the most of products remain in the solid but we do not deny that a small fraction (several percent) of the yield may desorb by the heat of reaction. 